\title{
Quantifying the need and potential of assisted migration
}

\section{Hällfors, Maria Helena}

2017

Hällfors , M H , Aikio , S A \& Schulman , L E 2017 , ' Quantifying the need and potential of assisted migration ' , Biological Conservation , vol. 205 , pp. 34-41 . https://doi.org/10.1016/j.biocon.2016.11.023

http://hdl.handle.net/10138/307745

https://doi.org/10.1016/j.biocon.2016.11.023

cc_by_nc_nd

acceptedVersion

Downloaded from Helda, University of Helsinki institutional repository.

This is an electronic reprint of the original article.

This reprint may differ from the original in pagination and typographic detail.

Please cite the original version. 
Hällfors et al.

1 Quantifying the need and potential of assisted migration.

2

3 Hällfors $\mathrm{MH}^{\mathrm{a}}$, Aikio $\mathrm{S}^{\mathrm{a}}$, Schulman $\mathrm{LE}^{\mathrm{a} *}$

4

5 a Botany Unit, Finnish Museum of Natural History, P.O. Box 7, FI-00014 University of Helsinki, $6 \quad$ Finland

7

8

9

* corresponding author: Leif Schulman, Finnish Museum of Natural History, P.O. Box 7, FI-

10

00014 University of Helsinki, Finland; leif.schulman@ @elsinki.fi, tel. +35850 5487692

11

12 Type of article: Perspective

13

14 Word count:

15 Abstract 250 words

$16 \quad$ Main text 5957 words

$17 \quad 43$ References

184 Figures \& Supplementary material

19

20

21

22

23

24

25 
Hällfors et al.

Assisted migration is recognized as a possible method for species conservation under climate change. Predicted decrease in range size and emergence of new suitable areas due to climate change are the main reasons for considering assisted migration. The magnitude of such changes can be used to guide decisions on the applicability of this conservation method. However, it has not been formalized how predictions acquired, e.g., with the help of species distribution models or expert assessments, should translate into recommendations or decisions. Climate change threat indices concentrating on predicted loss of habitat are not directly applicable in this context as they do not define whether a species has the potential to expand its range compared to the area that remains suitable. Here we present a conceptual framework for identifying and quantifying situations in which predictions indicate that a species could benefit from assisted migration. We translate predicted changes in suitable area into separate metrics for migration need and migration potential on the basis of the amount of lost, remnant, and new area. These metrics can be used as part of decision-making frameworks in determining the most suitable conservation method for a specific species. They also hold potential for coarser screening of multiple species to estimate the proportion of species that could benefit from assisted migration within a given time frame and climate change scenario. Furthermore, the approach can be used to highlight time frames during which assisted migration or, alternatively, other conservation actions are the most beneficial for a certain species.

Key words: adaptive management, assisted colonization, climate change, ecological niche modelling, managed relocation, translocation 
Hällfors et al.

51

52

53

54

55

56

57

58

59

60

61

62

63

64

65

66

67 To begin with, it should be noted that wide consensus on the acceptability of AM has not been

68

69

70

71

72

73

74

1. Introduction

Observed and potential effects of climate change on biodiversity are becoming evident (Dawson et al. 2011, Brommer et al. 2012, Urban 2015). A concern that traditional conservation methods may not be enough to safeguard species from decline has led to proposals of new proactive methods, such as actively moving species to new areas in pace with the changing climate (Peters \& Darling 1985; Hunter 2007, Schwartz et al. 2012). Although rarely implemented to date, this approach has been extensively discussed. It has variously been called assisted migration, assisted colonization, and managed relocation, among others, and also defined in different ways (Hällfors et al. 2014). In the strict sense, however, it is a type of conservation translocation (sensu IUCN 2012) in which species are moved from their indigenous range to areas where they would be predicted to move as climate changes, were it not for anthropogenic dispersal barriers or lack of time (see Hällfors et al. 2014 for a thorough discussion); here we refer to the method in this sense and call it assisted migration (AM). We use 'conservation' in the broad sense, i.e., include in it all actions aimed at safeguarding biodiversity, both preserving approaches and conservation management.

reached (Hewitt et al. 2011; Maier \& Simberloff 2016; Siipi \& Ahteensuu 2016). Nevertheless, AM has already been conducted for the conifer Torreya taxifolia in the USA (Barlow \& Martin 2004; Marris 2009) and for two butterfly species in the UK (Willis 2009), and is being considered, e.g., for the butterfly Euphydryas editha quino (Marris 2009). Hence, it is important to develop bestpractice guidelines for the possible future implementation of the method even if their application, in the end, may not turn into mainstream conservation practice. Indeed, several frameworks have been presented for guiding decisions on whether and when a species needs AM, for risk evaluation, and 
Hällfors et al.

for planning the process if deemed feasible (Hoegh-Guldberg et al. 2008; Richardson et al. 2009;

McDonald-Madden et al. 2011; Perez et al. 2012; Schwartz \& Martin, 2013).

Predictions of future changes in suitable areas have repeatedly been suggested as aids in evaluating the need of AM (Chauvenet et al., 2012; Schwartz, 2012; Guisan et al., 2013; Gallagher et al 2014). Such predictions can be derived at least through expert evaluation, mechanistic niche models, or species distribution models (SDMs). All these approaches contain uncertainties and caveats, such as biases in expert judgement, and assumptions on ecological equilibrium and local adaptation in niche models. These have been extensively discussed in the literature (Heikkinen et al. 2006; Araújo \& Peterson, 2012; Martin et al. 2012). However, the prediction methodology is continuously developing (Morin \& Thuiller 2009; Martin et al. 2012, Braunisch et al. 2013) and holds clear potential in this context as long as predictions are interpreted in the light of the limitations of the applied methodology. Nevertheless, it has not been established how the information obtained from predictions should be translated into decisions on whether or not to apply AM.

The absence of a recognized method for utilizing the information on range change predictions means that managers wishing to evaluate the appropriateness of AM are left with a recommendation on what tool to use but with no instructions on how to use it. This lack of guidance may result in subjective decisions and thereby inconsistent policy, or even in a status quo where no decisions are made, leading to a high risk of losing biodiversity in a rapidly changing world. A formal and rigorous way of utilizing range change predictions for the specific purpose of AM evaluations and decisions is therefore needed.

In evaluating species' vulnerability to and threat from climate change, formalizations of the use of modelling outputs have been put forward (e.g., Thomas et al. 2011, Maggini et al. 2014). Although 


\section{Hällfors et al.}

the proposed frameworks may be suitable for evaluating general threat from climate change, being vulnerable to climate change because of anticipated loss of distribution area does not necessarily mean that AM would be a suitable conservation method for the species. Instead, a combination of expected loss and gain of area is required for AM to be an appropriate response. A species that is not losing suitable habitat does not need to migrate and a species that will not have new climatically suitable area outside its current distribution area will not benefit from migration (with migration we mean the processes of dispersal, colonization, and establishment, which in the case of AM are aided by humans; Fig. 1). Hence, vulnerability assessments concentrating on species' sensitivity to climate change (see, e.g., Pacifici et al. 2015 for a review) are not sufficient to inform decisions regarding AM. Instead, both estimates on climate change exposure and on availability of new suitable area for translocations are necessary when deciding on and planning AM.

On the basis of our conceptualization of when a species would benefit from AM (Fig. 1), we present a straightforward method for converting predictions of changes in suitable area into metrics describing AM benefit. These metrics can be utilized in decision-making frameworks to answer those questions that concern range change. The predictions themselves can be constructed through a variety of methods, including not only correlative SDMs but also mechanistic models and expert evaluations, and be based on various data sources. Likely data include known species occurrences, climate variables, dispersal abilities, habitat requirements, habitat availability, and biotic interactions among species. The data needed for calculating the metrics we propose are readily obtainable from the range change predictions, provided these are quantifiable into spatial units, such as grid cells. The reliability of the results of predictions would largely depend on the degree of expert knowledge, the quality of the data, and other assumptions made in the process of obtaining the predictions. However, in this paper we do not attempt to test the usability of different prediction methods for range changes nor how different input data or modelling assumptions affect the 
Hällfors et al.

125 predictions. Instead, the aim is to describe a process that can be used for supporting decisions in 126 conservation once sufficiently reliable predictions on changes in suitable area are available (see

127 Hällfors et al. 2016 for a real-life application of the method described here).

128

129

130

2. Methods

131

132

2.1. Derivation of the AM metrics

133

134

135

Assisted migration, i.e., human-mediated dispersal to and establishment in new areas, may be applicable as a conservation method for species that meet the following criteria:

1. Migration need: Climate change, e.g.., changes in temperature and precipitation regimes, is predicted to render (part of) the species' current distribution area unsuitable.

2. Migration potential: Climate change is predicted to bring about new suitable area for the species.

3. Migration inability: The species either has poor intrinsic dispersal ability or faces anthropogenic dispersal barriers.

144 Criteria 1 and 2 can be quantified using predictions of changes in climatic conditions and

145 corresponding changes in suitable area, in addition to information on current distribution and habitat

146 preferences. In this paper and in the simulations we present, we treat suitable and unsuitable area in

147 a binary fashion. However, the suitability of the area could also be weighted by the probability of

148 suitability, or by some metric of habitat quality or carrying capacity, resulting in a correspondingly 
Hällfors et al.

149 scaled measure of suitable area. For the purpose of introducing our method, however, we here use a

150 simple binary approach with either suitable or unsuitable cells.

151

152 The metrics presented here are defined under the assumption of complete dispersal inability within

153 the considered time frame. Although this may be the worst case scenario of Criterion 3 for most

154 species, we consider it a suitable starting point and assessment background. When the approach

155 presented here is applied, information on dispersal ability, if available, can be incorporated into the development of range change predictions to obtain more realistic estimates.

157

158 The first metric is migration need, which we define as the relative need to compensate for the loss

159 of range caused by climate change. We quantify migration need at a given time $t\left(\mathrm{M}_{\mathrm{Need}, \mathrm{t}}\right)$ as the

160 proportion of a species' current distribution area that is projected to be lost due to climate change:

161

162

Eq. $1 \quad \mathrm{M}_{\text {Need }, \mathrm{t}}=\frac{\mathrm{A}_{\text {Original }}-\mathrm{A}_{\mathrm{Remnant}, \mathrm{t}}}{\mathrm{A}_{\text {Original }}}$

163

A Original is the size of the distribution area at the time $(t=0)$ selected as the initial point of the assessment (e.g., current distribution; preferably observed and verified occurrences, but alternatively modelled depending on species, method, and available data). ARemnant, is the part of Aoriginal that remains climatically suitable at a time $\mathrm{t}$ in the future.

$169 \mathrm{M}_{\text {Need,t }}=0$ means that the entire current distribution area is covered by projected future suitable 170 area, i.e., $A_{\text {Original }}=A_{\text {Remnant, },}$, which indicates no need for migration because of climate change

171 (other reasons, such as habitat destruction, may cause migration need, but in that case a possible

172 management intervention would be a conservation translocation other than AM; see definitions in 173 IUCN 2012 and Hällfors et al. 2014). The higher the value of $\mathrm{M}_{\text {Need,t, }}$, the more of the current 
Hällfors et al.

174 distribution area is projected to no longer be suitable, and at $\mathrm{M}_{\mathrm{Need}, \mathrm{t}}=1$ none of the species' current

175 area remains climatically suitable.

176

177 The second component, migration potential $\left(\mathrm{M}_{\text {Potential, }, t}\right)$, we define as the prospect of migration at

178 time $t$ when new area becomes suitable with changes in climate. We model $M_{\text {Potential, } t}$ as the

179 proportion of new suitable area from the total suitable area at a certain point in time:

180

181 Eq. 2

$$
\mathrm{M}_{\text {Potential,t }}=\frac{\mathrm{A}_{\mathrm{New}, \mathrm{t}}}{\mathrm{A}_{\mathrm{New}, \mathrm{t}}+\mathrm{A}_{\mathrm{Remnant}, \mathrm{t}}}
$$

182

$183 \mathrm{~A}_{\mathrm{New}, \mathrm{t}}$ is the area that was previously unoccupied but is projected to become suitable due to climate

184

change according to the predictions. We scale $A_{N e w, t}$ by the prospective future suitable area $\left(\mathrm{A}_{\mathrm{New}, \mathrm{t}}+\right.$ $\left.A_{\text {Remnant, }, t}\right)$, so that $M_{\text {Potential, } t}$ represents the potential for range expansion that a species has after the loss of its original area, i.e., what its potential is in relation to what it has left (the prospect of migration).

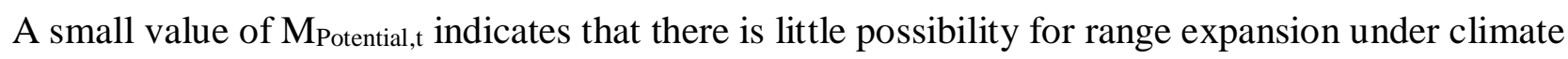
change compared to what the species has left $\left(A_{\text {Remnant, },}\right)$. The species will therefore benefit only marginally from migrating to the new area, as most of the available suitable area covers its original distribution. Conversely, a high $\mathrm{M}_{\text {Potential, }}$ value indicates that the species could increase its range considerably compared to what is left of Aoriginal if it were able to disperse.

For species that have limited ability to disperse fast enough on their own, the need for and potential of migration correspond to the need for and potential of AM. We therefore create a single metric with the name $\mathrm{I}_{\mathrm{AM}, \mathrm{t}}\left(\mathrm{AM}\right.$ index) composed of the geometric mean of its components $\mathrm{M}_{\mathrm{Need}, \mathrm{t}}$ and MPotential,t: 
Hällfors et al.

Eq. $3 \quad \mathrm{I}_{\mathrm{AM}, \mathrm{t}}=\sqrt{\mathrm{M}_{\text {Need }, \mathrm{t}} \cdot \mathrm{M}_{\text {Potential,t }}}$

201

202 We calculate the root of the product of $\mathrm{M}_{\mathrm{Need}, \mathrm{t}}$ and $\mathrm{M}_{\text {Potential,t }}$ to arrive at a constant rate of change of $\mathrm{I}_{\mathrm{AM}, \mathrm{t}}$ across low and high values of its components (when the components are in a constant ratio). This makes the index more sensitive to changes when at least one of the components is low. These properties facilitate comparison of the index across different species and climate change scenarios and the detection of small changes in $\mathrm{M}_{\mathrm{Need,t}}$ and $\mathrm{M}_{\text {Potential,t. }}$. High values of $\mathrm{I}_{\mathrm{AM}, \mathrm{t}}$ indicate that a species has both the need of AM and the potential to benefit from it. Hence, on the basis of range change evaluation, AM might be an appropriate approach in the conservation of this species.

$\mathrm{M}_{\text {Need,t, }}, \mathrm{M}_{\text {Potential,t }}$ and $\mathrm{I}_{\mathrm{AM}, \mathrm{t}}$ are all unitless metrics between zero and one. This facilitates their interpretation, and comparison between different species, future time periods, and climate change scenarios.

\subsection{Simulations}

215

We illustrate the behaviour of the metrics with simulated cases of possible changes in $A_{N e w, t}$ and $A_{\text {Remnant,t. }}$ The focus is on qualitatively different cases that are representative of possible changes in suitable area of species, and on the response of $\mathrm{I}_{\mathrm{AM}, \mathrm{t}}$ to these changes. Although real-life predictions would normally include climate change projections into only a few future time windows or time steps (e.g., the situation after three, five, and eight decades; see Hällfors et al. 2016) we use 50 time steps to showcase in greater detail how the metrics change through time. 


\section{Hällfors et al.}

In simulation group 1, changes in $A_{N e w, t}$ and $A_{\text {Remnant,t }}$ are modelled as simple but qualitatively differing functions. In accordance with criteria 1 and 2 above, we assume that climate change decreases $A_{\text {Remnant, }}$ and increases $A_{N e w, t}$ over time. We allow $A_{\text {Remnant,t }}$ and $A_{N e w, t}$ to change at different rates, and present different combinations with changes being initially fast or slow. We also consider a case of retrogression in $\mathrm{A}_{\mathrm{New}, \mathrm{t}}$, where $\mathrm{A}_{\mathrm{New}}$ first increases and later decreases, becoming zero by the end of the simulation (signifying that no more $A_{N e w}$ appears, which in real life could happen when the climatically suitable area moves northwards until the edge of a continent is reached, or up a mountain until the top is reached).

The temporal decrease in $A_{\text {Remnant, }}\left(\right.$ Fig. 2a) was modelled as $A_{\text {Remnant, } t}=1-\left(t / t_{\max }\right)^{\alpha}$, where $t$ is the time (arbitrary units) from current, $\mathrm{t}_{\max }$ is the time at which the simulation ends, and $\alpha$ is a shape parameter that defines whether the initial rate of change in $A_{\text {Remnant, }}$ is faster $(\alpha>1)$ or slower $(0<\alpha$ $<1)$ than linear. We used the values $\alpha=2$ and $\alpha=0.5$ for fast and slow initial change, respectively. The temporal increase of $A_{N e w, t}$ (Fig. 2b) was modelled as $A_{N e w, t}=\left(t / t_{m a x}\right)^{\alpha}$, with parameters as in $A_{\text {Remnant,t, }}$ except for the retrogression case that was modelled as $A_{N e w, t}=\max \left(0,-0.0005 \cdot t^{2}+\right.$ $0.04 \cdot \mathrm{t})$.

In simulation group 2, we mimic a possible progress of climate change by letting $A_{\text {Remnant,t }}$ and $A_{N e w, t}$ change over time depending on different patterns of viable landscape (Fig. 3). The simulation landscapes consist of $101 \times 50$ cell lattices, where the black and grey cells constitute the viable landscape where different parts are, have been, or will become suitable (see caption of Fig. 3), while the white cells remain non-viable throughout the simulations signifying habitat types that are unsuitable regardless of the climatic conditions. Suitable climate at each time step is represented as a square frame. It moves over the landscape, representing the change in climate, at a constant rate. Depending on its location, the sliding frame will cover a different part of the simulated landscape 
Hällfors et al.

248

and therefore contain a different number of viable cells, which will be made up from Remnant and New cells in different proportions. The direction of the movement represents the direction of climate change, which in real-life is typically towards the poles or upwards along an elevational gradient. The number of suitable landscape cells that fall within the square frame constitute the climatically (and otherwise) suitable area for the species at each time step. We can now simulate different scenarios of increase and decrease in $A_{N e w, t}$ and $A_{\text {Remnant, } t}$ by varying the pattern of viable landscape cells.

We generated different patterns of viable landscape with a first order autoregressive process (AR1), where the viability of a cell at the row $i$ and column $j$ of a landscape depends on the viability of its four neighbouring cells at the previous iteration step. This is calculated as $X_{i, j}^{\prime}=\varphi \cdot\left(X_{i-1, j}+X_{i+1, j}+\right.$ $\left.\mathrm{X}_{\mathrm{i}, \mathrm{j}-1}+\mathrm{X}_{\mathrm{i}, \mathrm{j}+1}\right) / 4+\varepsilon_{\mathrm{i}, \mathrm{j}}$, where $\mathrm{X}$ is the initial spatial configuration with a normally distributed random state $\varepsilon$ (zero mean, unit variance), and $\varphi$ is the autoregression coefficient (values $\varphi \leq 1$ are feasible). Cells with $X^{\prime}{ }_{i, j}>0$ are considered viable.

We used different values of $\varphi$ to generate patterns of different spatial autocorrelation. The first case (Fig. 3a, $\varphi=0$ ) represents complete spatial randomness, where the probability of a cell being viable is spatially independent $(\mathrm{p}=0.5)$. This represents a landscape that is uniform at a large scale but randomly patterned as viable or non-viable at a smaller scale. For instance, an insect specialised on living on pine trees could see a large tract of uniform boreal forest like this. The case also serves as a reference point for perhaps more common landscape patterns, where patches of suitable habitat are interspersed in a matrix of non-suitable habitats. These kinds of patterns are positively autocorrelated, i.e., a viable cell in our simulation landscape is more likely to have another viable cell as an immediate neighbour than an unviable one. 
Hällfors et al.

273 We modelled such cases with increasing values of the autoregression coefficient that result in 274 intermediate (Fig. 3b, $\varphi=0.900$ ) and high (Fig. 3c, $\varphi=0.999$ ) spatial autocorrelation. The 275 increasing size of landscape patches allows large variation in climatically suitable area between 276 sampling intervals. Each value of $\varphi$ was replicated 100 times to investigate the effect of a random 277 spatial pattern on $\mathrm{I}_{\mathrm{AM}, \mathrm{t}}$ (Fig. 3d) and on the difference between $\mathrm{M}_{\text {Potential, }}$ and $\mathrm{M}_{\text {Need,t }}$ (Fig. 3e) in 278 relation to AOriginal. The state of the replicated systems was investigated at $\mathrm{t}=25$, which corresponds 279 to the climatic frame having moved half of its length from the original position and allows for the 280 highest variance in original, remnant, and new areas.

281

We measured the degree of autocorrelation in the simulated landscape patterns using global Moran's I calculated with first degree neighbourhoods (Fortin and Dale 2005). The metric has been used for quantifying the degree of habitat fragmentation (e.g., Gao and Li 2011) and it facilitates the comparison of our simulated landscapes to patterns in nature. The value of global Moran's $I \approx 0$ represents complete spatial randomness in large samples, while $I=1$ results from the landscape being divided in two: a viable and an unviable half.

All computations were carried out using Matlab 8.5. (Release 2015a, The MathWorks Inc.). The scripts for generating the simulations and figures 2, 3, and 4 are distributed as Supplementary Data (Appendix A, B, and C).

2.3. Assisted migration threshold

There is no inherent threshold value of $\mathrm{I}_{\mathrm{AM}, \mathrm{t}}$ that would indicate range-change-associated benefit of AM for the species. Such thresholds could, however, be explored based on other widely applied 


\section{Hällfors et al.}

thresholds, e.g., those used in the Red List (IUCN, 2001) or the Climate Change Vulnerability Index (CCVI; Young et al., 2010). Thomas et al. (2011) presented an evaluation framework for incorporating Red List -inspired decadal losses and increases in species' ranges under climate change, with the purpose of recognizing threats and benefits of climate change. In their evaluation, a species receives a score of $0-3$ depending on the percentage of decline or increase in distribution per decade $(1-4 \% \rightarrow$ score of $1,4-7.5 \% \rightarrow 2,>7.5 \% \rightarrow 3)$. We calculated the values of $\mathrm{I}_{\mathrm{AM}, \mathrm{t}}$ that correspond to these categories to use as thresholds for deciding how beneficial, in terms of range change, AM would be as a conservation method for a species. If both $\mathrm{M}_{\mathrm{Need}, \mathrm{t}}$ and $\mathrm{M}_{\text {Potential, } \mathrm{t}}$ are above a certain threshold, AM could be a relevant method to consider in the conservation of the species in question.

To arrive at the thresholds, we first investigated a special case where $\mathrm{I}_{\mathrm{AM}, \mathrm{t}}$ only depends on $\mathrm{A}_{\text {Remnant, } \mathrm{t}}$ and its rate of decline over a number of decades. We ignore Eq. 2 for the moment, substitute $\mathrm{M}_{\text {Potential,t }}=1$ in Eq. 3, and assume that a species loses a constant proportion $\mathrm{p}_{\text {Loss }}$ of its range in each decade. ARemnant,t and the corresponding $\mathrm{M}_{\mathrm{Need}, \mathrm{t}}$ after $\mathrm{t}$ decades then become:

Eq. $4 \quad A_{\text {Remnant }, t}=A_{\text {Original }} \cdot\left(1-p_{\text {Loss }}\right)^{t}$

Eq. $5 \quad \mathrm{M}_{\mathrm{Need}, \mathrm{t}}=1-\left(1-\mathrm{p}_{\text {Loss }}\right)^{\mathrm{t}}$

The minimum requirement for a species to be recognized as climate change threatened, and to receive the score of 1 in Thomas et al.'s (2011) scaling, equals losing $1 \%$ of its range per decade (i.e., $\mathrm{p}_{\mathrm{Loss}}=0.01$ ) over the projected time span $\mathrm{t}=1$. Consequently, $\mathrm{M}_{\mathrm{Need}, 1}=0.01$ and $\mathrm{I}_{\mathrm{AM}, 1}=$ $(0.01 \cdot 1)^{1 / 2}=0.1$. In a similar way, $4 \%$ and $7.5 \%$ declines over a decade correspond to $\mathrm{I}_{\mathrm{AM}, 1}=0.2$ and $\mathrm{I}_{\mathrm{AM}, 1} \approx 0.27$, respectively. 


\section{Hällfors et al.}

323 We next considered how the formation of $A_{N e w, t}$ affects $I_{A M, t .}$ Following Thomas et al. (2011), we

324 assume that $A_{N e w, t}$ is formed as a proportion $\mathrm{p}_{\text {Gain }}$ of $A_{\text {Original }}$ and that the amount of $A_{N e w, t}$ is zero at $t$ $325=0$. The size of $\mathrm{A}_{\mathrm{New}, \mathrm{t}}$ and the corresponding $\mathrm{M}_{\text {Potential,t }}$ then become:

326

327

Eq. 6

$$
\mathrm{A}_{\mathrm{New}, \mathrm{t}}=\mathrm{A}_{\text {Original }} \cdot\left[\left(1+\mathrm{p}_{\text {Gain }}\right)^{\mathrm{t}}-1\right]
$$

328

Eq. 7

$$
\mathrm{M}_{\text {Potential, }}=\frac{\left(1+\mathrm{p}_{\mathrm{Gain}}\right)^{\mathrm{t}}-1}{\left(1+\mathrm{p}_{\mathrm{Gain}}\right)^{\mathrm{t}}+\left(1-\mathrm{p}_{\text {Loss }}\right)^{\mathrm{t}-1}}
$$

By substituting relevant factors in Eq. 3 with Eqs. 5 and 7, $\mathrm{I}_{\mathrm{AM}, \mathrm{t}}$ becomes a function of $\mathrm{p}_{\mathrm{Gain}}$ and

331 $\mathrm{p}_{\text {Loss, }}$ and the number of decades investigated. The time $\mathrm{t}$ is known from the point in time for which the prediction was made, and we can present the threshold values for one decade $(t=1)$ as $I_{\mathrm{AM}, 1}=$ $[0.1,0.2,0.27]$ in a parameter space of $\mathrm{p}_{\text {Loss }}$ and $\mathrm{p}_{\mathrm{Gain}}(\mathrm{Fig} .4 \mathrm{a})$. The loss rates are restricted to $0 \leq$ $\mathrm{p}_{\text {Loss }} \leq 1$, because AOriginal cannot decrease by more than $100 \%$, but no such restriction applies to the rate of increase in area (i.e., $p_{\text {Gain }} \geq 0$ ). With increasing $p_{\text {Gain }}$, the corresponding value of $p_{\text {Loss }}$ approaches the threshold values $\mathrm{I}_{\mathrm{AM}, 1}=[0.1,0.2,0.27]$. With decreasing $\mathrm{p}_{\mathrm{Gain}}$, the corresponding value of $\mathrm{p}_{\text {Loss }}$ approaches unity.

\section{Results}

As climate change causes progressive changes in $A_{N e w, t}$ and $A_{R e m n a n t, t}$ for a species (simulation group 1; Fig. 2a,b), the corresponding values of $\mathbf{M}_{\text {Need,t }}$ and $M_{\text {Potential,t }}$ form trajectories in the parameter space (Fig. 2d,e), where the value of the combined metric increases towards the top-right corner (Fig. 2c). Depending on the rate of change in $A_{R e m n a n t, t}$ and $A_{N e w, t}$, the relative magnitude of $\mathrm{M}_{\text {Need,t }}$ and $\mathrm{M}_{\text {Potential,t }}$ can vary, and the trajectories move above or below the diagonal that divides the parameter space. 
Hällfors et al.

349 When $A_{\text {Remnant,t }}$ decreases faster than $A_{N e w, t}$ increases, $M_{N e e d, t}$ is large relative to $M_{\text {Potential,t, }}$, and 350 trajectories move below the diagonal (Fig. 2d). Slow reduction in $A_{\text {Remnant,t }}$ combined with fast

351 increase in $\mathrm{A}_{\mathrm{New}, \mathrm{t}}$ results in large $\mathrm{M}_{\text {Potential, }}$ in relation to $\mathrm{M}_{\mathrm{Need}, \mathrm{t}}$, and trajectories progress above the 352 diagonal (Fig. 2e). A fast decrease in $A_{\text {Remnant, }}$ combined with equally fast increase in $A_{N e w, t}$ leads to 353 a trajectory that follows the diagonal (Fig. 2d). A slow decrease in ARemnant,t and slow increase in $354 \mathrm{~A}_{\mathrm{New}, \mathrm{t}}$ leads to a similar trajectory, but $\mathrm{I}_{\mathrm{AM}, \mathrm{t}}$ increases at a slower rate (Fig. 2e). $\mathrm{I}_{\mathrm{AM}, \mathrm{t}}$ can also 355 decrease if $A_{\text {Original,t }}$ and $A_{N e w, t}$ do not change at an even rate. For example, if $A_{N e w, t}$ first increases and then decreases, $\mathrm{I}_{\mathrm{AM}, \mathrm{t}}$ similarly first increases and then decreases (Fig. 2e).

Under complete spatial randomness of viable and non-viable cells (simulation group 2; Fig. 3a),

$\mathrm{M}_{\text {Need,t }}$ and $\mathrm{M}_{\text {Potential, }}$ increase at the same rate, owing to equally many new cells becoming suitable at the leading edge (top) of the sliding sampling frame (i.e., the 'changing climate') as originally suitable cells become unsuitable at the trailing edge (bottom) of the frame. At each advancing simulation step, $A_{\text {Remnant,t }}$ therefore decreases by the same amount as $A_{N e w, t}$ increases, with slight variation coming from the randomness in the distribution of viable cells. As a consequence, there is little variation in $\mathrm{A}_{\text {original }}$ and $\mathrm{I}_{\mathrm{AM}, \mathrm{t}}$ between replicates of the pattern-generating process (Fig. $3 \mathrm{~d}$ ), and $\mathrm{M}_{\text {Need }}$ and $\mathrm{M}_{\text {Potential }}$ are nearly equal (Fig. 3e). This indicates that the trajectory of $\mathrm{I}_{\mathrm{AM}, \mathrm{t}}$ would follow the diagonal of the $\mathrm{M}_{\text {Need }}$ vs. M $\mathrm{M}_{\text {Potential }}$ parameter space (cf. Fig. 2c).

When the degree of spatial autocorrelation takes intermediate (Fig. 3b) or high (Fig. 3c) values, $\mathrm{A}_{\text {original }}$ and $\mathrm{I}_{\mathrm{AM}, \mathrm{t}}$ vary more, and there is more variation in the relative magnitudes of $\mathrm{M}_{\mathrm{Need,t}}$ and $M_{\text {Potential,t }}$ (Fig. 3e). If this was presented in the parameter space of $M_{\text {Need,t }}$ vs. $M_{\text {Potential, }}($ Fig. 2c), the trajectory of $\mathrm{I}_{\mathrm{AM}, \mathrm{t}}$ would in many cases be far from the diagonal and could also move from one side of the diagonal to the other. Increasing spatial autocorrelation also brings about a negative 
Hällfors et al.

373 relationship between $\mathrm{A}_{\text {original }}$ and $\mathrm{I}_{\mathrm{AM}, \mathrm{t}}$ (Fig. 3d), and the value of $\mathrm{M}_{\text {Potential, }}$ decreases in relation to

$374 \mathrm{M}_{\text {Need,t }}$ when $\mathrm{A}_{\text {original }}$ increases (Fig. 3e). The first relationship shows that species already occupying

375 most of the viable cells in the landscape do not benefit from AM. The second relationship shows

376 that the decrease in $\mathrm{I}_{\mathrm{AM}, \mathrm{t}}$ with increasing proportion of viable cells in $\mathrm{A}_{\text {original }}$ results from a decrease

377 in $M_{\text {Potential,t. The values of the autoregression coefficient } \varphi \text { used for simulating landscape patterns }}$

378 resulted in large differences in degree of autocorrelation as measured by Moran's I. Complete

379 spatial randomness $(\varphi=0)$ led to Moran's $I=-0.0023 \pm 0.0066$ (mean \pm SD), while the

380 autoregressive process with $\varphi=0.9$ and $\varphi=0.999$ corresponded to $I=0.35 \pm 0.01$ and $I=0.73 \pm$

3810.03 , respectively.

382

383 Our translation of Thomas et al.'s (2011) climate change threat scores into critical values of I $\mathrm{AM}_{\mathrm{A}, \mathrm{t}}$

384 can be interpreted so that, when $\mathrm{I}_{\mathrm{AM}, \mathrm{t}}$ is calculated based on predictions extending one decade into 385 the future, a species with $0.1<\mathrm{I}_{\mathrm{AM}, 1}<0.2$ is a possible candidate for AM, a species with $0.2<\mathrm{I}_{\mathrm{AM}, 1}$ $386<0.27$ is a probable candidate for $\mathrm{AM}$ and a species with $\mathrm{I}_{\mathrm{AM}, 1}>0.27$ is a strong candidate for $\mathrm{AM}$ 387 (Fig. 4a). For a prediction 100 years into the future (10 decades) the corresponding thresholds for $388 \mathrm{I}_{\mathrm{AM}, 10}$ are $0.31,0.58$, and 0.74 (Fig. $4 \mathrm{~b}$ ).

\section{Discussion}

The parameter space formed by all possible values of $\mathrm{M}_{\mathrm{Need}, \mathrm{t}}$ and $\mathrm{M}_{\text {Potential, } \mathrm{t}}$ shows the nonlinear relationship between $\mathrm{I}_{\mathrm{AM}, \mathrm{t}}$ and its components (Fig. 2c). At the combined low $\mathrm{M}_{\mathrm{Need}, \mathrm{t}}$ and low $M_{\text {Potential,t }}$ (Fig. 2c: lower left corner of the parameter space), the low value of $\mathrm{I}_{\mathrm{AM}, \mathrm{t}}$ indicates that a species is neither losing its current range nor gaining new migration opportunities (Fig. 1a). This could happen in reality, e.g., when a species has a wide distribution area to start with 
Hällfors et al.

398

399

400

401

402

403

404

405

406

407

408

409

410

411

412

413

414

415

416

417

418

419

420

421

422

(geographically or as regards climatic variation), or when it occurs in an area that is climatically relatively stable even in the face of global change, such as refuge areas during Pleistocene climatic oscillations. Alternatively, a species may be so strongly limited by other factors than climate that a change in climate does not lead to a marked change in its distribution. Examples include some plant species adapted to serpentine soils (Damschen et al. 2012).

When one of the components $\left(\mathrm{M}_{\mathrm{Need}, \mathrm{t}}\right.$ or $\left.\mathrm{M}_{\text {Potential, }, \mathrm{t}}\right)$ is very small, $\mathrm{I}_{\mathrm{AM}, \mathrm{t}}$ may not exceed the threshold for the species to be considered a candidate for AM even if the other component is substantially larger. This implies that AM is likely a poor conservation choice, since there is either little threat of losing area or little new area available to translocate the species to. Therefore, a low $\mathrm{I}_{\mathrm{AM}, \mathrm{t}}$ for a certain species would support a decision of no intervention, if there is no threat of losing area, or the application of actions other than AM in the conservation of the species, if there is loss of current area but no emerging new area. If only $\mathrm{M}_{\mathrm{Need}, \mathrm{t}}$ is high (Fig. 1b; Fig. 2c: lower right-hand part of parameter space), the need for conservation is certainly more urgent than if only $\mathrm{M}_{\text {Potential, }}$ is high (Fig. 1c; Fig. 2c: upper left-hand part), but AM is not an applicable method, as there would be no suitable area to which the species could be assisted to migrate. Alternative conservation strategies might then involve increased in situ management, ex situ conservation, or even conservation introduction (IUCN 2012), i.e., translocating the species to any environmentally suitable area outside of its indigenous range, where the species could not move on its own even with time, such as another continent.

Only a species that gains new suitable area at the same time as it loses previously suitable area (Fig. 1d; Fig 2c: centre to upper right part of parameter space), but has difficulties in dispersing on its own, is a clear candidate for AM. Changes in climatically suitable area of this kind are likely to occur in settings lacking an elevational gradient and where an edge of a continent is not 
Hällfors et al.

423 immediately reached (for an example of a dispersal-limited desert tree in Africa, see Foden et al.

424

425

426

427

428

429

430

431

432

433

434

435

436

437

438

439

440

441

442

443

444

445

446

447 2007).

Spatial autocorrelation increased variance in AOriginal of the modelled hypothetical species, and led to variation in the value of $\mathrm{I}_{\mathrm{AM}, \mathrm{t}}$ and the relative magnitude of its components (Fig. 3d,e). The variance allows us to see the negative correlation between AOriginal and $\mathrm{I}_{\mathrm{AM}}$. When most of the viable cells are within the original area, the result is a low $\mathrm{I}_{\mathrm{AM}, \mathrm{t}}$ (Fig. 3d) and a relatively low $\mathrm{M}_{\text {Potential,t }}$ (Fig. 3e). In the opposite case, where most of the viable cells in the landscape are outside the original area (small Aoriginal), climate change will result in a high proportional loss of the original area and a large proportional gain of new area in comparison to remnant area, which leads to a high $\mathrm{I}_{\mathrm{AM}}$ (Fig. 3d) and a relatively high $\mathrm{M}_{\text {Potential,t }}$ (Fig. 3e). We can therefore expect a negative relationship between AOriginal and $\mathrm{I}_{\mathrm{AM}, \mathrm{t}}$ to arise from the spatial distribution of viable landscape cells. This pattern emerged in a study where the method presented here was applied to real-world species using range change predictions derived through SDMs (Hällfors et al. 2016). Based on the present simulation results, the relationship between $\mathrm{A}_{\text {Original }}$ and $\mathrm{I}_{\mathrm{AM}, \mathrm{t}}$, or the relative magnitude of its components should not automatically be attributed to biological processes or species characteristics without additional evidence, as the relationship can simply result from landscape patterns.

Nevertheless, in real-life situations a large $\mathrm{I}_{\mathrm{AM}, \mathrm{t}}$ for a species with a small AOriginal can also reflect an ecologically relevant process for rare species: as climate change makes large parts of the original area unsuitable, even if not much new area is gained, the proportional importance of the new area increases, since remnant area is scarce. In such cases a high $\mathrm{I}_{\mathrm{AM}, \mathrm{t}}$ value correctly reflects the need and potential of AM, even though focal translocation areas may be limited.

Natural landscapes have values of Moran's I that correspond to our simulated landscapes. The intermediate landscape ( $\varphi=0.9$; Moran's $I=0.36)$ falls in the range of values estimated for urban 
Hällfors et al.

448 landscape of Shenzhen in Guangdong Province in South China $(I=0.28-0.55$; Gao and Li 2011)

449 and the estimated $I=0.44$ for the pattern of architectural landscape in Jinan, China (Xue et al.

450 2015). These urban landscapes represent a higher degree of fragmentation than the protected areas

451 in northern New England (Meyer et al. 2015), where the highest values of Moran's $I>0.70$ are

452 similar to the landscapes we simulated with the highest autoregression coefficient $(\varphi=0.999)$.

453

454 We harmonized our conceptualization and metrics with the climate change threat scale of Thomas

455 et al. (2011) by using the same percentage rates of change in $A_{R e m n a n t, t}$ and $A_{N e w, t}$ as they did for loss

456 and gain, and by calculating the corresponding combined values of the metrics for these thresholds.

457 Applying this framework in evaluating AM suitability for real species should provide useful

458 experience and insight into the functionality of this approach and the suggested thresholds. It is

459 important to note, however, that placing species in these categories does not alone determine how

460 appropriate AM would be in each case. Species recognised as strong AM candidates based on the

$461 \mathrm{I}_{\mathrm{AM}, 1}>0.27$, will additionally have to be subjected to more detailed analyses on the ecological,

462 economic, societal, legal, and ethical applicability of AM (e.g., IUCN 2012, Peréz et al. 2012,

463 Maier \& Simberloff 2016; Siipi \& Ahteensuu 2016). But without a rigorous measure of the need

464 and potential for migration, suggesting whether AM could be the appropriate method, when it

465 comes to geographical shifts in the species' suitable area, such further considerations are premature.

467 We see the formalization of migration need and potential presented here as a useful tool in two 468 main situations:

469 (1) Determining the most suitable conservation method and, in particular, evaluating the spatial applicability of AM in conservation planning for a specific species. 
Hällfors et al.

471

472

473

474

475
(2) Screening of large numbers of species to gain understanding about what proportion of a regional biota might be in need of AM within a given time frame under a certain climate change scenario.

In the first situation, the formalization can be used as part of decision-making frameworks (e.g., Perez et al. 2012; Schwartz \& Martin 2013) to provide objective, quantitative answers to questions concerning future decline and increase of suitable area. Here, its novelty comes from specifically relating predictions in range change to the ecological usefulness of AM. The approach thus provides instructions on how to apply previously identified tools, such as correlative species distribution models and expert predictions of range change, in the context of decision-making concerning AM.

Obviously our method does not, however, represent a statement regarding how generally recommendable $\mathrm{AM}$ of the species is.

An additional benefit of the AM index calculations is that they can provide guidelines on the applicability and timing of application of other conservation methods too. If, for instance, $\mathbf{M}_{\mathrm{Need}, \mathrm{t}}$ rapidly increases within the coming decades, while $\mathrm{M}_{\text {Potential,t }}$ remains low, it may be advisable to opt for designing and carrying through an ex situ conservation programme for the species. Since the development of $\mathrm{I}_{\mathrm{AM}}$ is non-linear, predictions further into the future may suggest that eventually new climatically suitable area will appear, and then the ex situ population of the species could be used for an introduction of the species into the newly emerged suitable area, should it be deemed otherwise acceptable. This could be described as a delayed AM procedure, where the calculation of $\mathrm{I}_{\mathrm{AM}}$ and its components gave impetus to the intermediate ex situ conservation stage. Alternatively, if $\mathrm{M}_{\text {Need,t }}$ increases only gradually, while the increase in $\mathrm{M}_{\text {Potential, },}$ is delayed, more intensive in situ management in the current distribution area may be the best option. This could help a population 
Hällfors et al.

stay viable until new climatically suitable area appears where the population can migrate (or be assisted to migrate).

In the second situation, screening large numbers of species, formalized metrics make it possible to calculate comparable percentages of species that could benefit from AM for different points in time, e.g., after two, five, or eight decades. Here, the important aspect of our AM metrics is that their values are likely to change non-linearly over time as climate change progresses in real-world settings (see Hällfors et al. 2016). Hence they have the potential of highlighting time frames during which specific conservation actions are the most beneficial, or even at all possible, for a certain species. For instance, if the proportion of the biota needing AM increases considerably after five decades, it is probably advisable to strive for avoiding that situation, e.g., through investing in enhancing natural dispersal by increasing connectivity between habitat patches, since large-scale $\mathrm{AM}$ is likely to be considerably challenging and costly, and may be challenged on other grounds too (Maier \& Simberloff 2016). Hence, the metrics introduced here can highlight resource need for conservation under different climate change scenarios and help resource managers to plan ahead. Moreover, scenarios like this can further emphasize the need to mitigate climate change, rather than relying on adaptation to it.

The approach presented here can thus be used in a similar manner as the Red List Index (Butchard et al. 2007). The Red List Index describes observed changes in species' threat status, and serves as an evaluative and political tool for assessing conservation trends. However, our metrics concern anticipating future challenges, rather than evaluating past changes. It is therefore important to recognize the many uncertainties involved in methods for predicting change in suitable area (Heikkinen et al. 2006; Martin et al. 2012). These include epistemic uncertainties regarding our incomplete knowledge on the environmental requirements of species as well as uncertainty in 
Hällfors et al.

520 human decisions ranging from expert judgments to climate change mitigation. Although some of

521 this uncertainty can be handled or at least apprehended through ensemble modelling (Araújo and

522 New 2007; for application in the context of the method described here, see Hällfors et al. 2016), the

523 reliability of predictions will continue to depend on the quality and validity of the data and theory

524 used to develop them. However, because our metrics are based on explicit data and formalized

525 calculations, they have the advantage of being comparatively easy to update and re-evaluate as new

526 data and refined prediction methods become available.

527

528 Acknowledgements

529 MHH was supported by LUOVA - Doctoral Programme in Wildlife Biology Research. SA was

530 supported by the Academy of Finland [grant number 258144] and by the Kone Foundation. We are

531 grateful to the CO-ADAPT research group for comments and discussions. We thank anonymous

532 reviewers for constructive comments on earlier versions of the manuscript.

533

534 Glossary

535 Assisted migration = safeguarding biological diversity through the translocation of representatives

536 of a species or population harmed by climate change to an area outside the indigenous range of that

537 unit where it would be predicted to move as climate changes, were it not for anthropogenic

538 dispersal barriers or lack of time (Hällfors et al. 2014).

539 Migration $=$ the processes of dispersal, colonization, and establishment, which in the case of

540 assisted migration are aided by humans.

541 Aoriginal = current distribution (observed or modelled depending on the species and available

542 occurrence data) of a species (measured in number of grid cells, $\mathrm{km}^{2}$, or similar).

543 A Remnant, $=$ the part of Aoriginal that remains suitable at a certain point of time in the future

544 (measured in number of grid cells, $\mathrm{km}^{2}$, or similar). 
Hällfors et al.

$545 \mathbf{A}_{\text {New, }}=$ the area (number of grid cells, $\mathrm{km}^{2}$, or similar) that was previously unoccupied or

546 unsuitable but has become suitable due to climate change.

547 MPotential, $\mathbf{t}=$ Migration potential, the prospect of migration when new area becomes suitable with

548 change in climate, calculated as the proportion of new suitable area $\left(\mathrm{A}_{\mathrm{New}, \mathrm{t}}\right)$ from the total suitable

549 area $\left(A_{R e m n a n t, t}+A_{N e w, t}\right)$ at a certain point in time. A high value of $M_{\text {Potential, }}$ indicates that climate

550 change offers the species relatively large potential for range expansion compared to what it has left.

$551 \mathbf{M}_{\text {Need,t }}=$ Migration need, the relative need to compensate for the loss of range by climate change,

552 calculated as the proportion of a species' original distribution area (AOriginal) that will be lost due to

553 climate change $\left(A_{\text {Original, } t}-A_{\text {Remnant, }, t}\right)$. A high value of $M_{N e e d, t}$ indicates that climate change turns a

554 relatively large part of the original area unsuitable wherefore the species has a high need for range

555 expansion to maintain a distribution area of the same size.

$556 \mathbf{I}_{\mathbf{A M}}=$ the geometric mean of $\mathrm{M}_{\mathrm{Need,t}}$ and $\mathrm{M}_{\text {Potential,t, }}$ indicating, on a scale between 0-1, how relevant 557 assisted migration might be for the species.

558

559 Appendix A. Supplementary data

560 Appendix B. Supplementary data

561 Appendix C. Supplementary data

562 Supplementary data associated with this article can be found, in the online version, at http:

$563 / / d x$. doi.org/10.1016/...

564

565

566 References

567 Araújo, M.B., New, M. 2007. Ensemble forecasting of species distributions. Trends Ecol. Evol. 22, $568 \quad 42-7$. 
Hällfors et al.

570

$571 \quad 1539$.

572

573

574

575

576 577 climate change. Ecography. 36(9), 971-983.

578

579

580

581

582

583

584

585

586

587

588

589

590

591

592

593

594 ONE 2(1), e140. DOI: 10.1371/journal.pone.0000140 Ecology 100: 1122-1130.

Araújo, M.B., Peterson, A.T. 2012. Uses and misuses of bioclimatic modelling. Ecology 93, 1527-

Barlow, C., Martin, P.S. 2004. Bring Torreya taxifolia north - now. Wild Earth, Winter/Spr., 52-56.

Braunisch, V., Coppes, J., Arlettaz, R., Suchant, R., Schmid, H., Bollmann, K. 2013 Selecting from correlated climate variables: a major source of uncertainty for predicting species distributions under

Brommer, J.E., Lehikoinen, A., Valkama, J. 2012. The breeding ranges of central European and arctic bird species move poleward. PLOS ONE 7, e43648. DOI: 10.1371/journal.pone.0043648

Butchart, S.H.M., Akçakaya, H.R., Chanson, J., Baillie, J.E.M., Collen, B., Quader, S., Turner, W.R., Amin, R., Stuart, S.N., Hilton-Taylor, C. 2007. Improvements to the Red List Index. PLOS

Chauvenet, M., Ewen, J.G., Armstrong, D.P., Blackburn, T.M., Pettorelli, N. 2012. Maximizing the success of assisted colonizations. Animal Conservation 16(2), 161-169.

Damschen, E.I., Harrison, S., Ackerly, D.D., Fernandez-Going, B.M., Anacker, B.L. 2012. Endemic plant communities on special soils: early victims or hardy survivors of climate change? Journal of

Dawson, T.P., Jackson, S.T., House, J.I., Prentice, I.C., Mace, G.M. 2011. Beyond predictions: biodiversity conservation in a changing climate. Science 332(6025), 53-8. 
Hällfors et al.

596 Foden, W., Midgley, G.F., Hughes, G., Bond, W.J., Thuiller, W., Hoffman, M.T., Kaleme, P., 597 Underhill, L.G., Rebelo, A., Hannah, L. 2007. A changing climate is eroding the geographical range 598 of the Namib Desert tree Aloe through population declines and dispersal lags. Diversity and 599 Distributions 13, 645-653.

600

601 Gallagher, R.V., Makinson, R.O., Hogbin, P.M., Hancock, N. 2014. Assisted colonization as a 602 climate change adaptation tool. Austral Ecology 40(1), 12-20.

603

604 Gao, J., Li, S. 2011. Detecting spatially non-stationary and scale-dependent relationships between 605 urban landscape fragmentation and related factors using Geographically Weighted Regression. 606 Applied Geography 31, 292-302.

607

608 Guisan, A., Tingley, R., Baumgartner, J.B. et al. 2013. Predicting species distributions for 609 conservation decisions. Ecology Letters, 16(12), 1424-1435.

610

611 Hällfors, M.H., Vaara, E.M., Hyvärinen, M., Oksanen, M., Schulman, L.E., Siipi, H., Lehvävirta, S. 612 2014. Coming to Terms with the Concept of Moving Species Threatened by Climate Change - A

613 Systematic Review of the Terminology and Definitions. PLOS ONE 9(7), e102979. 614 doi:10.1371/journal.pone.0102979

615

616 Hällfors, M.H., Aikio, S., Fronzek, S., Hellmann, J.J., Ryttäri, T., Heikkinen, R.K. 2016. Assessing 617 the need and potential of assisted migration using species distribution models. Biological 618 Conservation 196, 60-68. http://dx.doi.org/10.1016/j.biocon.2016.01.031 619 
Hällfors et al.

620 Heikkinen, R.K., Luoto, M., Araújo, M.B., Virkkala, R., Thuiller, W., Sykes, M.T. 2009. Methods

621 and uncertainties in bioclimatic envelope modeling under climate change. Progress in Physical

622 Geography 30, 751-777.

623

624 Hewitt, N., Klenk, N., Smith, A.L. et al. 2011. Taking stock of the assisted migration debate.

625 Biological Conservation 144, 2560-2572.

626

627

Hijmans, R.J., Cameron, S.E., Parra, J.L., Jones, P.G., Jarvis, A. 2005. Very high resolution

628

interpolated climate surfaces for global land areas. International Journal of Climatology 25, 1965-

6291978.

630

631 Hunter, M.L. 2007. Climate change and moving species: furthering the debate on assisted

632

colonization. Conservation Biology 21, 1356-8.

633

634 Hoegh-Guldberg, O., Hughes, L., Mcintyre, S., Lindenmayer, D.B., Parmesan, C., Possingham,

635 H.P., Thomas, C.D. 2008. Assisted Colonization and Rapid Climate Change. Science 321, 345-346.

636

637

IUCN 2001. IUCN Red List Categories and Criteria: Version 3.1. IUCN Species Survival

638

Commission, IUCN, Gland, Switzerland and Cambridge, UK.

639

640 IUCN 2012. IUCN Guidelines for Reintroductions and Other Conservation Translocations. Gland,

641 Switzerland.

642

643 Maggini, R., Lehmann, A., Zbinden, N. et al. 2014. Assessing species vulnerability to climate and

644 land use change: the case of the Swiss breeding birds. Diversity and Distributions 20, 708-719. 
Hällfors et al.

646 Maier, D.S, Simberloff, D. 2016. Assisted migration in normative and scientific context. Journal of 647 Agricultural and Environmental Ethics. doi:10.1007/s10806-016-9628-5

648

649 Marris, E. 2008. Moving on assisted migration. Nature Reports Climate Change 2: 112-113. doi:

$650 \quad 10.1038 /$ climate.2008.86

651

652

Martin, T.G., Burgman, M. A., Fidler, F., Kuhnert, P. M., Low-Choy, S., McBride, M., Mengersen, 653

K. 2012. Eliciting Expert Knowledge in Conservation Science. Conservation Biology 26, 29-38.

654

655 McDonald-Madden, E., Runge, M.C., Possingham, H.P., Martin, T.G. 2011. Optimal timing for 656 managed relocation of species faced with climate change. Nature Climate Change 1, 261-265.

657

658 Meyer, S.R., Beard, K., Cronan, C.S., Lilleholm, R.J. 2015. An analysis of spatio-temporal 659 landscape patters for protected areas in northern New England: 1900-2010. Landscape Ecology 30, 660 1291-1305.

661

662 Morin, X., Thuiller, W. 2009. Comparing niche- and process-based models to reduce prediction 663 uncertainty in species range shifts under climate change. Ecology 90(5), 1301-1313.

664

665 Pacifici, A.M., Foden, W., Visconti, P., et al. 2015. Assessing species vulnerability to climate 666 change. Nature Climate Change 5, 215-225.

667 
Hällfors et al.

668 Pérez, I., Anadón, J.D., Díaz, M., Nicola, G.G., Tella, J.L., Giménez, A. 2012. What is wrong with 669 current translocations? A review and a decision-making proposal. Frontiers in Ecology and the 670 Environment 10, 494-501.

671

672 Peters, R.L., Darling, J.D.S. 1985. The Greenhouse Effect and Nature Reserves. Bioscience 35, $673 \quad 707-717$.

674

675 Phillips, S., Anderson, R., Schapire, R. 2006. Maximum entropy modeling of species geographic 676 distributions. Ecological Modelling 190(3-4), 231-259.

677

678 Richardson, D.M., Hellmann, J.J., McLachlan, J.S. et al. 2009. Multidimensional evaluation of 679 managed relocation. Proceedings of the National Academy of Sciences 106, 9721-9724.

680

681

Schwartz, M.W. 2012. Using niche models with climate projections to inform conservation

682 management decisions. Biological Conservation 155, 149-156.

683

684

Schwartz, M.W., Hellmann, J.J., McLachlan, J.S. et al. 2012. Managed Relocation: Integrating the 685 Scientific, Regulatory, and Ethical Challenges. Bioscience 62, 732-743.

686

687

Schwartz, M.W., Martin, T.G. 2013. Translocation of imperiled species under changing climates.

Ann. N. Y. Acad. Sci. 1286, 15-28.

689

690 Siipi, H., Ahteensuu, M. 2016. Moral relevance of range and naturalness in assisted migration.

691 Environmental Values 25, 465-483.

692 
Hällfors et al.

693 Thomas, C.D., Hill, J.K., Anderson, B.J. et al. 2011. A framework for assessing threats and benefits

694 to species responding to climate change. Methods in Ecology and Evolution 2, 125-142.

695

696 Thuiller, W., Lafourcade, B., Engler, R., Araujo, M.B. 2009. BIOMOD - A platform for ensemble 697 forecasting of species distributions. Ecography 32, 369-373.

698

699 Urban, M.C. 2015. Accelerating extinction risk from climate change. Science 348(6234), 571-573.

700

701 Willis, S.G., Hill, J.K. Thomas, C.D. Roy, D.B. Fox, R. Blakeley, D.S. and Huntley, B. 2009.

702 Assisted colonization in a changing climate: a test-study using two U.K. butterflies. Conservation

703 Letters 2, 46-52.

704

705 Young, B., Byers, E., Gravuer, K., Hammerson, G., Redder, A. 2010. Guidelines for using the

706 NatureServe Climate Change Vulnerability Index. Arlington, VA: NatureServe.

707

708 Xue, C., Zheng, X., Zhang, B., Yuan, Z. 2015. Evolution of a multidimensional architectural

709 landscape under urban regeneration: a case study of Jinan, China. Ecological Indicators 55, 12-22.

710

711

712

713

714

715

716

717 
Hällfors et al.
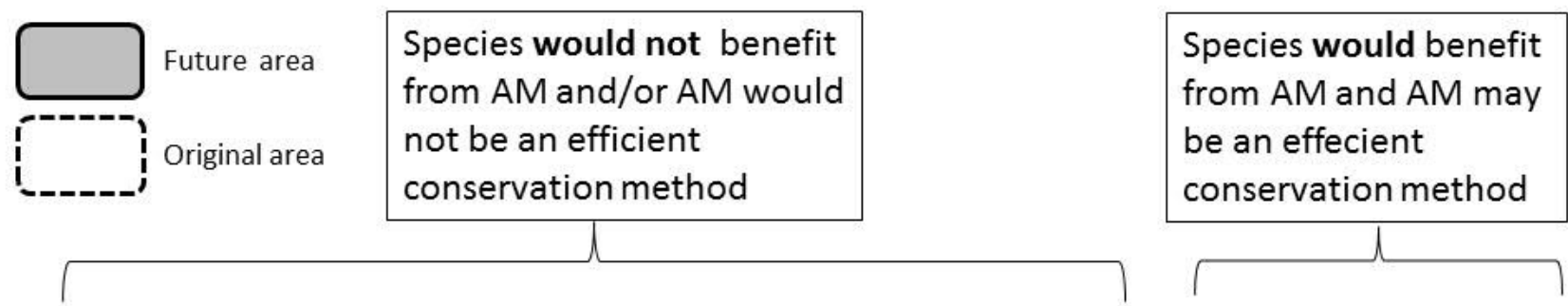

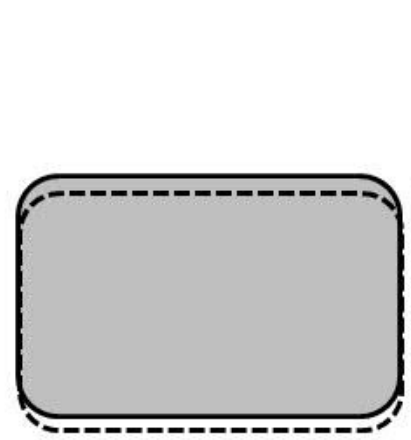

(a) Minimal loss of original area and minimal future suitable area - range of species not threatened by climate change

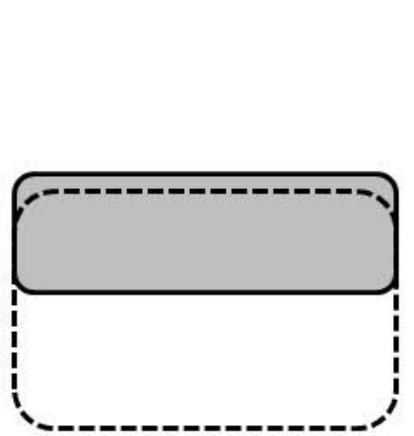

(b) Substantial loss of original area and minimal future suitable area range of species threatened by climate change but species not an AM candidate

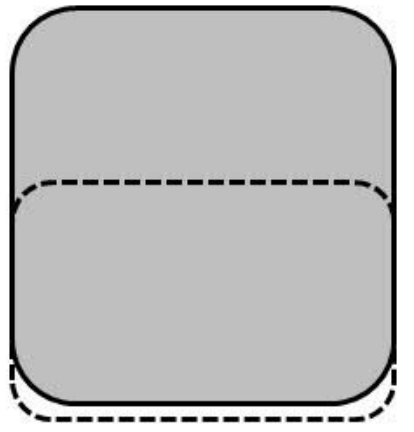

(c) Minimal loss of original area and substantial future suitable area - range of species not threatened by climate change

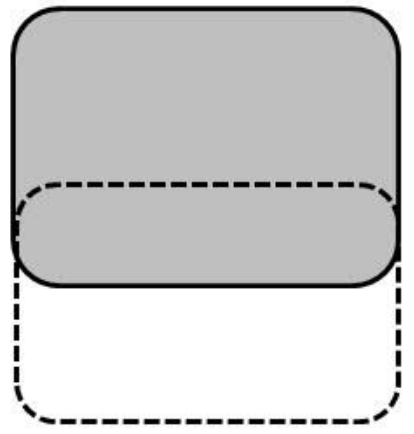

(d) Substantial loss of original area and substantial future suitable area - range of species threatened by climate change and the species is an AM candidate

Fig. 1. Conceptualization of assisted migration (AM; sensu Hällfors et al. 2014) candidacy any of the three future scenarios (a-c), the species in question either does not need AM or does not

727 have the potential of shifting its distribution because new area does not become available. The fourth scenario (d) suggest that AM could be an appropriate conservation method for this species. 
Hällfors et al.
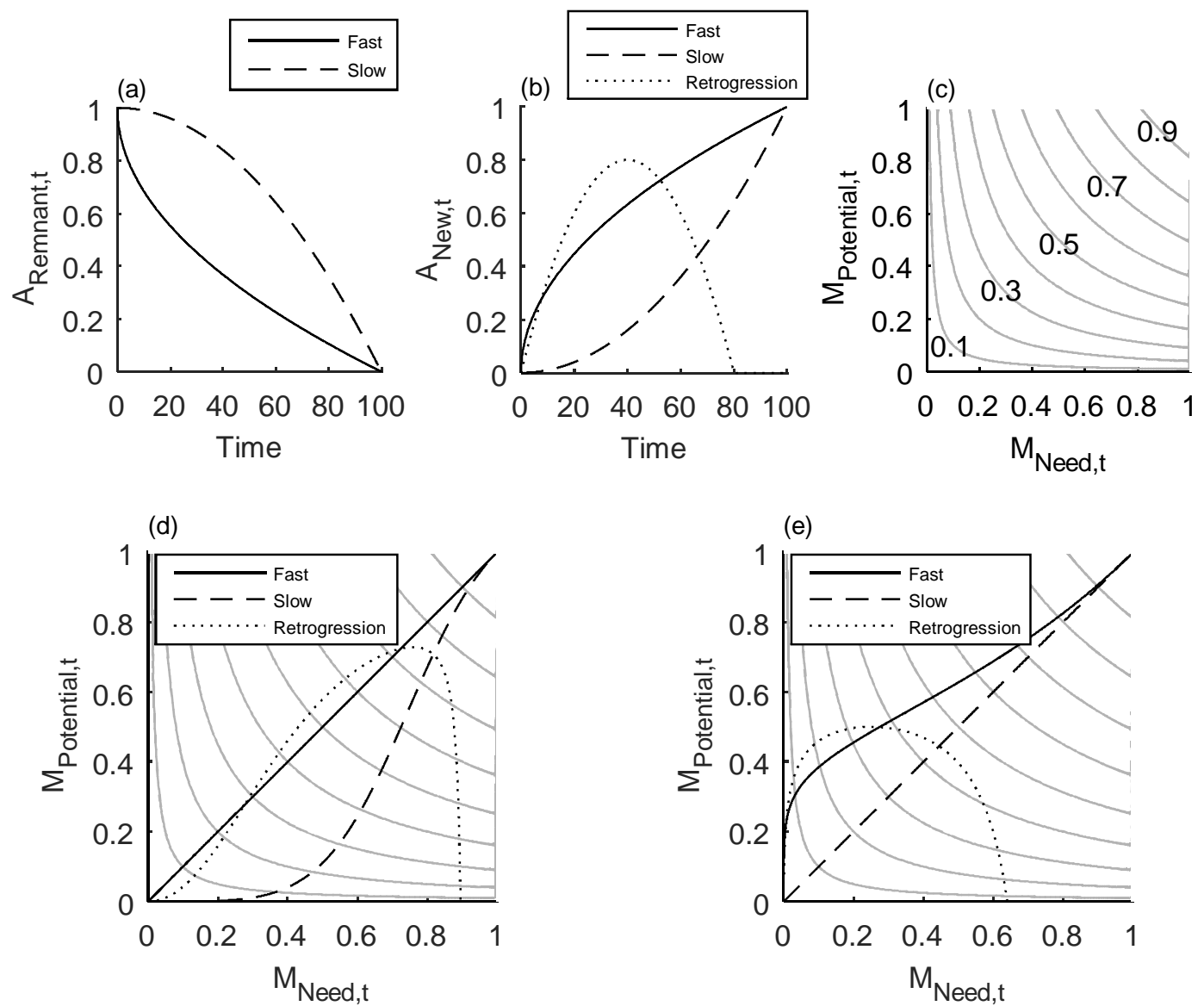

731

Fig. 2. Simulated development of remnant and new areas ( $A_{\text {Remnant }}$ and $A_{N e w}$, respectively) and the corresponding $\mathrm{M}_{\mathrm{Need}, \mathrm{t}}, \mathrm{M}_{\text {Potential,t, }}$ and $\mathrm{I}_{\mathrm{AM}, \mathrm{t} .}$ Scenarios for temporal development of (a) $\mathrm{A}_{\text {Remnant,t }}$ and (b) $A_{N e w, t}$, under simulated climate change, and (c) a parameter space plot with the axes $M_{N e e d, t}$ and $M_{\text {Potential, }}$ and the corresponding values of $\mathrm{I}_{\mathrm{AM}, \mathrm{t}}$ (isoclines at 0.1 unit intervals). The lower panels show trajectories of $\mathrm{I}_{\mathrm{AM}, \mathrm{t}}$ corresponding to the three scenarios of $\mathrm{A}_{\mathrm{New}, \mathrm{t}}$ development shown in $\mathrm{b}$, that are combined with $A_{\text {Remnant,t }}$ decreasing initially at a (d) fast, and (e) slow rate, as in panel a. AOriginal $=1$ in all cases.

739 
Hällfors et al.
(a) $\phi=0$
(b) $\phi=0.9$
(c) $\phi=0.999$

Moran's $I=0$

Moran's I $=0.33$

Moran's $I=0.67$

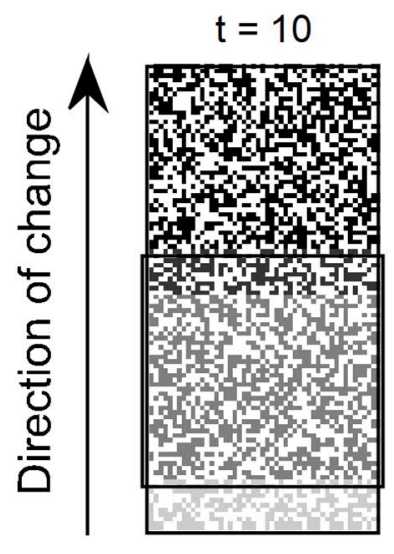

$t=20$
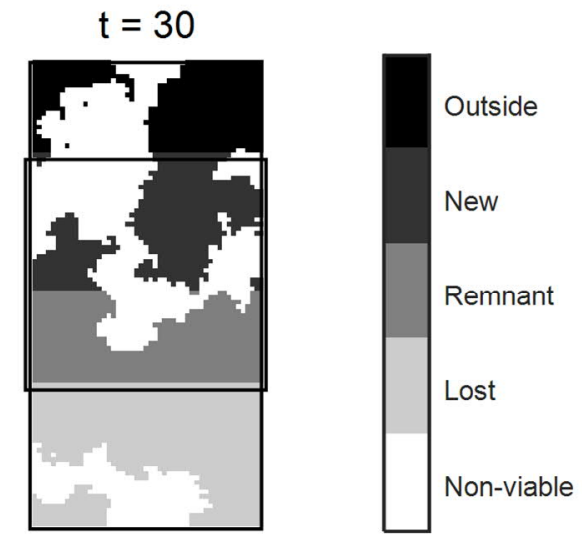

743
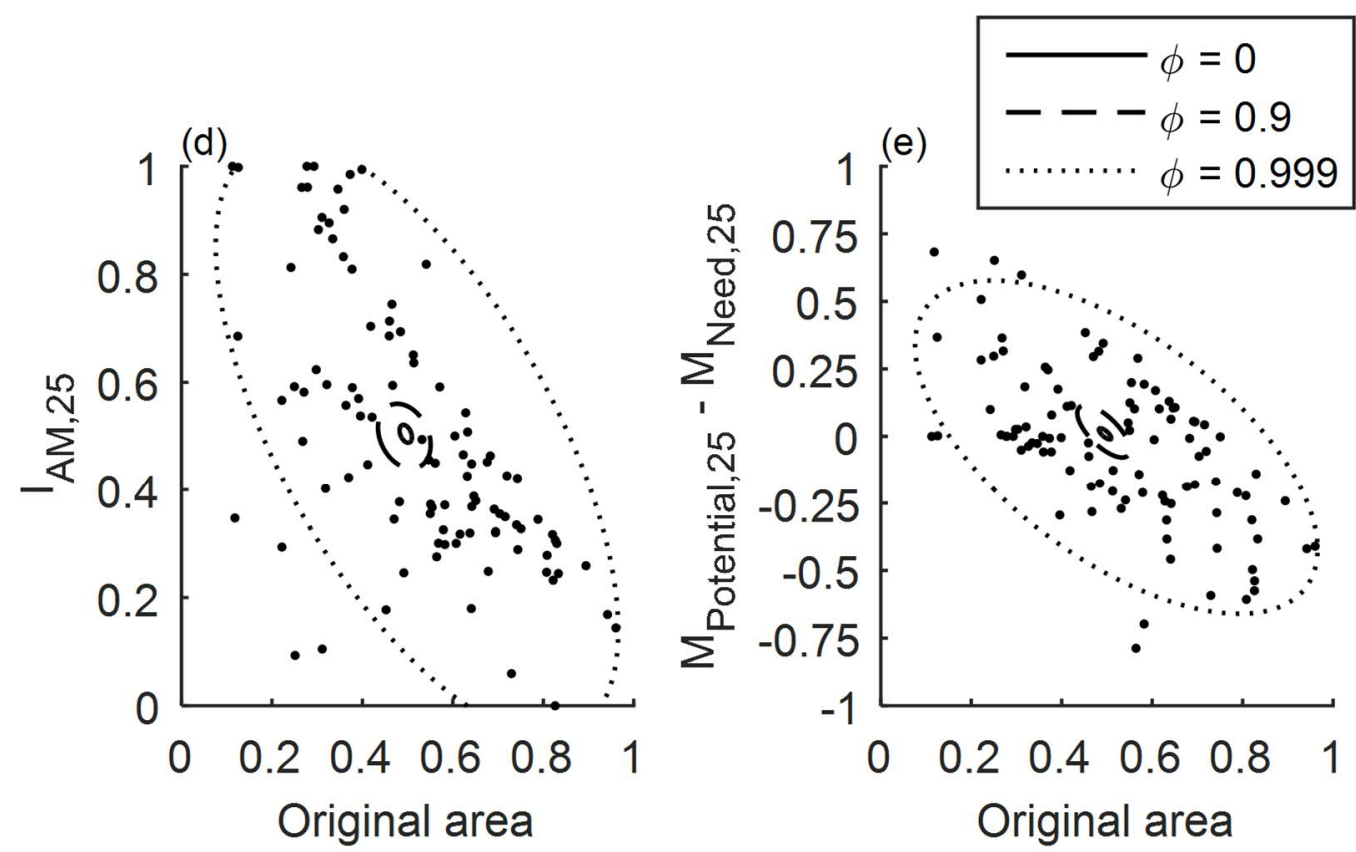

744

Fig. 3. (a-c) Examples of lansdcape patterns of viable (black and grey) and non-viable (white) cells

simulated with different values of first order autoregression parameter phi and the corresponding measure of spatial autocorrelation as global Moran's I (first neighbours). The climatic suitability of cells is determined by a square frame representing the area of suitable climate. The frame moves over the landscape one cell row at the time in a bottom to top direction representing climate change, e.g., pole- or upward movement of mean temperature or other climatic variable(s). At the beginning of the simulation, the climatic frame coincides with the original area (AOriginal). As the climatic 


\section{Hällfors et al.}

752 frame moves over the landscape, some cells initially part of AOriginal become unsuitable (i.e., Lost),

753 while others remain suitable (Remnant). Cells that were not part of AOriginal but become suitable by

754 the movement of the climatic frame constitute the New area. The Outside cells represent the area

755 that has not yet become climatically suitable, but may in the future be part of the New area. The

756 panels (a-c) illustrate the location of the climatic frame at different time steps $(t=10,20,30$ cells or

757 time steps upwards from the bottom). Panels $d$ and e show $\mathrm{I}_{\mathrm{AM}, \mathrm{t}}$ and the difference between $\mathrm{M}_{\mathrm{Need}, \mathrm{t}}$

758 and $\mathrm{M}_{\text {Potential,t }}$ at the time $\mathrm{t}=25$ in relation to the original area. The dots are replicates of the

759 landscapes simulated with $\varphi=0.999$ and the dotted ellipse is a $95 \%$ confidence ellipse fitted to the

760 scatterplot. For clarity, the scatterplot of other values of $\varphi$ are omitted and these cases are

761 represented only by their confidence ellipses.

762

763 
Hällfors et al.

(a)

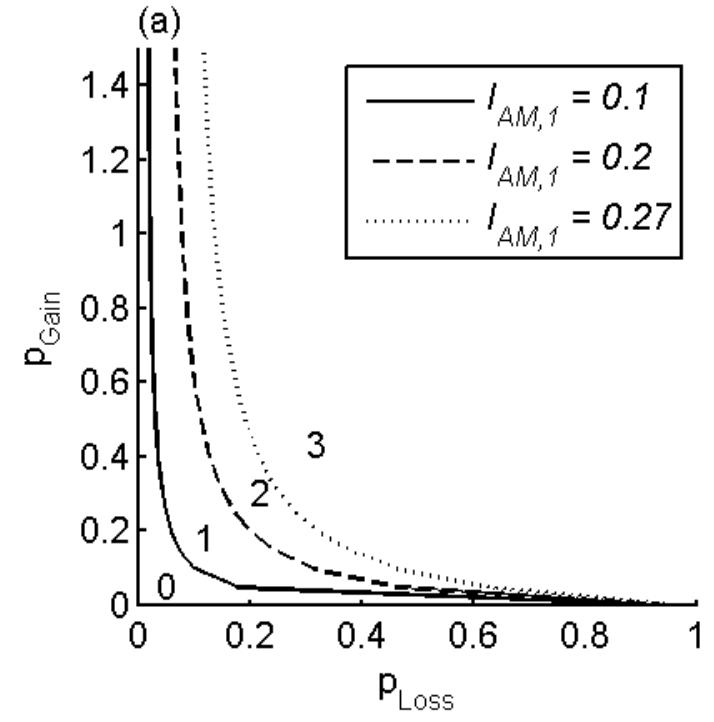

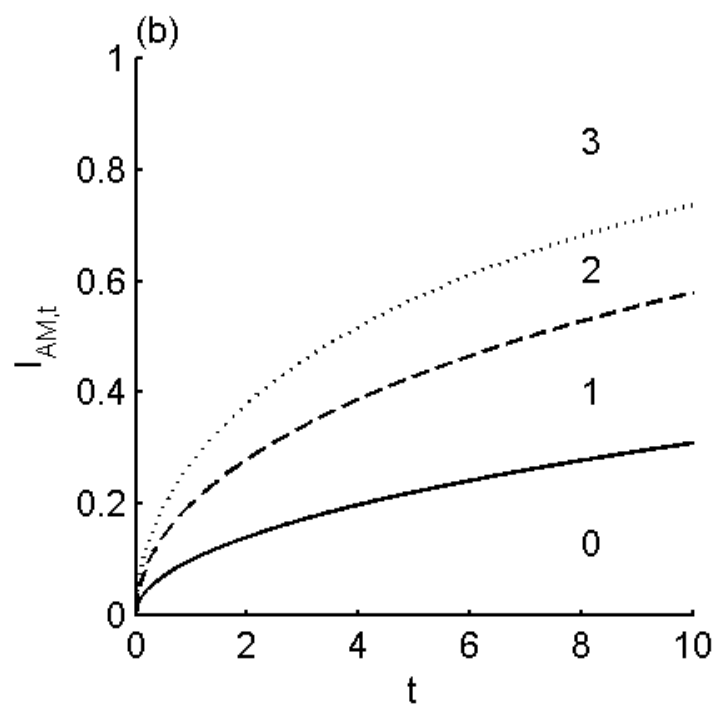

764

765 Fig. 4. a) AM index $\left(\mathrm{I}_{\mathrm{AM}, 1}\right)$ as a function of proportional loss of area $\mathrm{p}_{\mathrm{Loss}}$ and gain of area pain per

766 decade. The threshold values $\mathrm{I}_{\mathrm{AM}, 1}=[0.1,0.2,0.27]$ correspond to 1,4 and $7.5 \%$ reduction rates

767 evaluated over a single decade $(t=1)$. b) $I_{A M, t}$ thresholds for scores of $0-3$ over $0-10$ decades $(t)$,

768 where the scores are: $0=$ not a candidate for AM; $1=$ possible candidate for AM; $2=$ probable

769 candidate for AM; and 3 = strong candidate for AM.

770 